\title{
Overweight and Obesity among 25-60 Years Women in Lahore, Pakistan
}

\author{
Rukiya Tariq ${ }^{*}$, Ahmed Tariq ${ }^{2}$, Kalsoom Tariq ${ }^{3}$, Ayesha Shahid ${ }^{4}$, Maryam Shahid ${ }^{5}$ and Abdullah Hussain ${ }^{6}$ \\ 'Public Health, Department of Public Health, University of the Punjab, Lahore, Pakistan; rukiyatariq17@gmail.com \\ 2House Officer, Sharif Medical and Dental College, Lahore, Pakistan; ahmed.tariq.1217@gmail.com \\ ${ }^{3}$ Fatima Memorial Hospital College of Medicine and Dentistry, Lahore, Public Health, Department of Public Health, \\ University of the Punjab, Lahore, Pakistan; kalsoomtariq5@gmail.com \\ ${ }^{4}$ PG Trainee in Obstetrics and Gynaecology, Sheikh Zayed Hospital, Lahore, Pakistan; shahid.ayesha72@gmail.com \\ ${ }^{5}$ PG Trainee in Pediatric Medicine, Mayo Hospital, Lahore, Pakistan; maryam.shahid.100@gmail.com \\ ${ }^{6}$ Medical Officer, Mayo Hospital, Lahore, Pakistan; abdullah.hussain.94@hotmail.com
}

\begin{abstract}
Objective: To observe association of factors such as nutritional factors, physical activities and systemic factors with overweight and obesity among 25 to 60 years old women. Study Design: A quantitative household survey. Place and Duration: The survey was carried out in all ten towns of Lahore, Pakistan from $4^{\text {th }}$ January 2016 to $4^{\text {th }}$ May 2016. Methodology: The research investigated 3239 women ( 25 to 60 years of age) through multistage sampling technique; from which two neighboring localities were randomly selected; found 1106 women were overweight and 449 were obese whereas, 1684 females were normal weights who were excluded from the research study. Results: Factors were found significantly associated with overweight and obesity. Among nutritional factors such as fast food and snacks have $p$-value 0.000 , whereas, daily food intakes have $p$-value 0.001 . Physical activities such as housework activities have p-value 0.000; whereas, both regular exercise and time spent on TV/Computer per day have p-values 0.001. Systemic factors such as systemic diseases have p-value 0.001 whereas family history of overweight and obesity and women using medications both have p-value 0.000 . Conclusion: The study concluded that overweight and obesity was positively associated with nutritional factors, physical activities and factors such as genetics, use of medications and systemic diseases among women 25-60 years.
\end{abstract}

Keywords: Household Survey, Nutritional Factors, Obesity, Overweight, Physical Activities, Systemic Factors

\section{Introduction}

The studies done from all over the world have shown that overweight and obesity are global public health problems, particularly among women belonging to urban settings. Globally, 2.8 million people being overweight or obese die yearly; whereas, internationally approximately 35.8 million DisabilityAdjusted Life Years (DALYs) are the reason of overweight and obesity ${ }^{1}$. Since obesity is observed by the influence of genetic factors due to which food intake and metabolic pathways may be disturbed ${ }^{2,3}$. High fat diet (such as fast food, snacks) and lack of physical activity all lead to increase in Body Mass Index ${ }^{4,5}$. A household survey ${ }^{6}$ conducted on 5127 individuals in Punjab and India found that among women, lifestyle and diet were the most important risk factors to explain the differences between urban and rural residents. Whereas, a close relationship ${ }^{7}$ found between Body Mass Index and physical activity during an analysis in the cross-sectional study on 426 female students, 18 to 25 years old at Guilan University. The study shows prevalence as $11.9 \%, 3.1 \%$ and $6.4 \%$ of overweight, obesity and abdominal obesity respectively while physical activity in three levels (light, moderate, heavy) were reported as $67.1 \%, 13.1 \%$ and $19.8 \%$ respectively. The study concluded that positive association exists between Body Mass Index (BMI) and physical activity, whereas low physical activity found to be as an independent risk factor of overweight and obesity (OR $=1.7$ with $15 \%$ CI: $1.1-2.5$ and $\mathrm{p}=0.03)$. Also weight gain is very common, but often unnoticed among individuals with widespread side effects of using antidepressant and antipsychotic medications ${ }^{8}$ and having systemic diseases such as hypertension, diabetes, cardiovascular diseases, musculoskeletal disorders, cancers (breast cancer and uterine cancer), menopause and polycystic ovarian syndrome ${ }^{9,10}$. In Pakistan, study was found on comorbidities with overweight and obesity ${ }^{11}$. But there is

${ }^{*}$ Author for correspondence 
no previous study conducted in Pakistan on factors such as nutritional factors and physical activities causing overweight and obesity among women. Therefore, the present study was carried out to communicate factors associated with overweight and obesity among 25 to 60 years women in Lahore, Pakistan. As in the last decades, the fast food restaurants were not in abundance and people use to eat homemade meals. Now burgers, shawarma, snacks etc. are available in almost every roadside kiosk, which are not hygienic and can cause many diseases with overweight and obesity. In addition, systemic diseases, use of medications, family history of weight gain, stress and anxiety due to deviations in social setup and the environmental factors and decrease in physical activities in women can result in overweight and obesity. Therefore, this research is being done on women as they have rich body fats than men and in the above-mentioned circumstances; a remarkable increase of overweight and obese women can be noted.

\section{Methodology}

\subsection{Study Design}

A quantitative household survey.

\subsection{Place and Duration}

The survey was carried out in all ten towns of Lahore, Pakistan from $4^{\text {th }}$ January 2016 to $4^{\text {th }}$ May 2016.

\subsection{Objective}

To observe association of factors such as nutritional factors, physical activities and systemic factors with overweight and obesity among 25 to 60 years old women.

\subsection{Inclusion Criteria}

The area of focus for conducting research is on overweight and obese women 25 to 60 years of age. The reason of choosing this age group was the turning point of any woman towards various susceptible diseases, which may be transformed to chronic diseases. This can be prevented if proper care and preventive measures was taken into account. Since the occurrence rate of diseases in the normal weight women is comparatively low as they take proper care of themselves and are very conscious about their diet.

\subsection{Exclusion Criteria}

Pregnancy and breastfeeding are natural phenomena and weight gain in it is obvious. Therefore, normal weight (i.e. Body Mass Index), pregnant and lactating women were excluded from the research.

\subsection{Sampling Technique}

The research investigated 3239 women ( 25 to 60 years of age) through multistage sampling technique; from which two neighboring localities were randomly selected namely; Sadar Bazar and Badian Road from the Aziz Bhatti Town; Tufail Road and Sarwar Road in Lahore Cantt; Gulshan Ravi and Muzang Chungi from Data Gunj Bakhesh Town; Gulberg III and Model Town from Gulberg Town; Johar Town and Wapda Town from Allama Iqbal Town; Cavalry Ground and DHA in Nishtar Town; Bhatti Gate and Kashmiri Bazar from Ravi Town; Allama Iqbal Town and Muslim Town from Samanabad Town; Baghbanpura old and Shadbagh from Shalimar Town and DaroghWala and Rivaz Garden from Wagha Town; thus found 1106 women were overweight and 449 were obese whereas, 1684 females were normal weights who were excluded from the research study.

\subsection{Data Collection Tool}

A primary data was obtained by using a structured interview questionnaire in English language, which was translated into local language (Urdu) for better understanding of respondents as well as their height and weight were also measured using weighing scale and retractable steel measure tape ruler. The pretesting of questionnaire was done before data collection procedure in order to ensure the accurateness, workability, as well as strength of the research tool.

\subsection{Statistical Analysis}

Data was analyzed by IBM SPSS Statistics version 21.0. Binary logistic regression was applied to examine the unadjusted consequences of the independent variables on every outcome in the form of odd ratio with $95 \%$ Confidence Interval.

\subsection{Ethical Approval}

Before data collection initiation, written informed consent was taken from 25 to 60 years overweight and obese women. This information was explained sufficiently to the women that they would be treated with full respect and dignity. During research study, respondent's privacy and anonymity was maintained and also ensured that their information will be remained confidential in future.

\section{Results}

A total of 3239 women were observed from which 1555 (48\%) overweight/obese women belonging to different settings of Lahore, Pakistan met the inclusion criteria and 1684 (52\%) females with normal weight were excluded because they did not meet the inclusion criteria. Out of 1555 (48\%) respondents, 
1106 overweight and 449 obese women were found as per study protocol and their data were analyzed. Clearly, out of 3239 , 1106 (34\%) overweight and 449 (14\%) obese women were investigated. Binary logistic regression was applied in order to estimate the factors causing overweight and obesity among 25 to 60 years women. The results concluded from (Table 1) that among nutritional factors; high odd ratio was found in obese women (2.50 (2.05-3.05)) as compared to overweight women (2.22 (1.96-2.51)) who often eat fast food and snacks. Obesity showed high odd ratio among women (2.28 (1.52-3.43)) than overweight women $(2.06(1.61-2.62))$ who eat more than 5 times a day. A positive association was found between nutritional factors with overweight and obesity; such as fast food and snacks has p-value 0.000 , whereas daily food intake has p-value 0.001 .

Table 2, showed that among physical activities; highest odd ratio was found both in overweight and obese women who often carry out housework activities i.e. 2.05 (1.64-2.56) and 1.92 (1.65-2.41) respectively. Exercise is the major phenomena to remain healthy and fit. High Odds Ratio was found among overweight women (2.70 (1.88-3.89)) who do not do regular exercise. Obesity showed high odd ratio among women who spent more time on TV/Computer per day as 2.39 (1.91-3.01). Overweight and obesity showed positive association with physical activities such as housework activities has p-value 0.000 , whereas, both regular exercise and time spent on TV/ Computer per day have p-values 0.001 .

Obesity showed high odds ratio among women who have systemic diseases as $4.62(2.37-7.57)$ whereas, high odds ratio was observed in overweight women who have family history of weight gain (1.68 (1.38-2.14)) and using medications

Table 1. Association of nutritional factors causing overweight and obesity among 25 to 60 years women

\begin{tabular}{|c|c|c|c|}
\hline \multicolumn{4}{|c|}{$\begin{array}{l}\text { Association of nutritional factors causing overweight and obesity } \\
(\mathrm{N}=1555)\end{array}$} \\
\hline \multirow[t]{2}{*}{ Factors } & \multicolumn{2}{|c|}{$\begin{array}{l}\text { Odds Ratio (OR) } \\
\text { 95\% Confidence Interval }\end{array}$} & \multirow[t]{2}{*}{ P-value } \\
\hline & Overweight & Obese & \\
\hline \multicolumn{4}{|c|}{ Fast Food and Snacks } \\
\hline $\begin{array}{l}\text { Often } \\
\text { Sometimes } \\
\text { Never }\end{array}$ & $\begin{array}{c}2.22(1.96-2.51) \\
1.78(1.38-2.31) \\
\mathbf{1}\end{array}$ & $\begin{array}{c}2.50(2.05-3.05) \\
1.84(1.51-2.09) \\
\mathbf{1}\end{array}$ & 0.000 \\
\hline \multicolumn{4}{|c|}{ Daily Food Intake } \\
\hline $\begin{array}{l}2-3 \text { times } \\
4-5 \text { times } \\
\text { More than } \\
5 \text { times }\end{array}$ & $\begin{array}{c}\mathbf{1} \\
1.76(1.39-2.31) \\
2.06(1.61-2.62)\end{array}$ & $\begin{array}{c}\mathbf{1} \\
1.34(1.07-1.68) \\
2.28(1.52-3.43)\end{array}$ & 0.001 \\
\hline
\end{tabular}

$1=$ Reference category.
Table 2. Association of physical activities with overweight and obesity among 25 to 60 years women

\begin{tabular}{|c|c|c|c|}
\hline \multicolumn{4}{|c|}{$\begin{array}{l}\text { Association of physical activities with overweight and obesity } \\
(\mathrm{N}=1555)\end{array}$} \\
\hline \multirow[t]{2}{*}{ Factors } & \multicolumn{2}{|c|}{$\begin{array}{l}\text { Odds Ratio (OR) } \\
\text { 95\% Confidence Interval }\end{array}$} & \multirow[t]{2}{*}{$\mathrm{P}$-value } \\
\hline & Overweight & Obese & \\
\hline \multicolumn{3}{|c|}{ Housework Activities } & \multirow[b]{2}{*}{0.000} \\
\hline $\begin{array}{l}\text { Often } \\
\text { Sometimes } \\
\text { Never }\end{array}$ & $\begin{array}{c}2.05(1.64-2.56) \\
1.57(1.33-1.86) \\
\mathbf{1}\end{array}$ & $\begin{array}{c}1.92(1.65-2.41) \\
1.19(1.06-1.34) \\
\mathbf{1}\end{array}$ & \\
\hline \multicolumn{3}{|c|}{ Regular Exercise } & \multirow[b]{2}{*}{0.001} \\
\hline $\begin{array}{l}\text { Often } \\
\text { Sometimes } \\
\text { Never }\end{array}$ & $\begin{array}{c}\mathbf{1} \\
2.11(1.65-2.25) \\
2.70(1.88-3.89)\end{array}$ & $\begin{array}{c}\mathbf{1} \\
2.33(2.05-2.59) \\
2.48(2.31-2.72)\end{array}$ & \\
\hline \multicolumn{3}{|c|}{ Time spent on TV/Computer per day } & \\
\hline $\begin{array}{l}\text { 1-3 hours } \\
4-6 \text { hours } \\
\text { More than } \\
7 \text { Hours } \\
\text { Never }\end{array}$ & $\begin{array}{l}1.60(1.48-2.15) \\
1.85(1.54-2.37) \\
1.93(1.67-2.42)\end{array}$ & $\begin{array}{c}1.43(1.04-2.08) \\
1.61(1.27-2.50) \\
2.39(1.91-3.01) \\
\mathbf{1}\end{array}$ & 0.001 \\
\hline
\end{tabular}

$1=$ Reference category.

Table 3. Association of systemic factors causing overweight and obesity among 25 to 60 years women

\begin{tabular}{|c|c|c|c|}
\hline \multicolumn{4}{|c|}{$\begin{array}{l}\text { Association of systemic factors causing overweight and obesity } \\
(\mathrm{N}=1555)\end{array}$} \\
\hline \multirow[t]{2}{*}{ Factors } & \multicolumn{2}{|c|}{$\begin{array}{l}\text { Odds Ratio (OR) } \\
\text { 95\% Confidence Interval }\end{array}$} & \multirow[t]{2}{*}{ P-value } \\
\hline & Overweight & Obese & \\
\hline \multicolumn{4}{|c|}{ Systemic Diseases } \\
\hline $\begin{array}{l}\text { Yes } \\
\text { No }\end{array}$ & $\begin{array}{l}2.48(1.75-3.18) \\
1\end{array}$ & $\begin{array}{c}4.62(2.37-7.57) \\
\mathbf{1}\end{array}$ & 0.001 \\
\hline \multicolumn{4}{|c|}{ Medications } \\
\hline $\begin{array}{l}\text { Yes } \\
\text { No }\end{array}$ & $\begin{array}{l}4.16(2.87-6.05) \\
1 \\
\end{array}$ & $\begin{array}{c}2.39(1.91-3.01) \\
1 \\
\end{array}$ & 0.000 \\
\hline \multicolumn{4}{|c|}{ Family history of overweight and obesity } \\
\hline $\begin{array}{l}\text { Yes } \\
\text { No }\end{array}$ & $\begin{array}{l}1.68(1.38-2.14) \\
1\end{array}$ & $\begin{array}{l}1.43(1.02-1.99) \\
1\end{array}$ & 0.000 \\
\hline
\end{tabular}

$1=$ Reference category.

(4.16 (2.87-6.05)). The positive association was observed between overweight and obesity with systemic factors such as systemic diseases have p-value 0.001 whereas women using medications and family history of overweight and obesity both have p-values 0.000 as shown in (Table 3 ). 


\section{Discussion}

The energy-rich foods such as low nutrients foods such as fast foods (pizza, burger, shawarma) and snacks (biscuit, chips, fried potatoes, fried chicken, cake, pastry, chocolates) were rich in fats and sugar resulting increase in weight gain of individuals. Our study showed statistical significance relationship of energy-rich foods and low nutrients foods with overweight and obesity having p-values 0.001 and 0.000 respectively. These study findings were well supported by ${ }^{12}$ as well as by ${ }^{13}$ that high energy foods, snacks and fast foods consumption may influence the increase of Body Mass Index resulting in overweight and obese individuals.

The results are based on the observed trend towards decrease in regular exercise and more involvement of overweight/obese women towards housework activities. The study findings were supported by ${ }^{14}$ that marriage may come with much physical, psycho-social and financial support from both partner and relations that facilitate comfort and a tendency for lessened physical activities or energy expenditure together with variations in standards of living may be accompanying with weight gain. Moreover, in most of the marriages, fertility or number of children are expected to increase, which culturally causes increased food intake and dwindling physical activities on the part of woman spouse ${ }^{15}$.

A high level of sitting time was also a risk factor in women. The study findings showed that women who watch TV, 4-6 hours were found overweight whereas obesity was found in women who watch TV more than 7 hours. Possibly watching TV for more than 3 hours was occasioned by recurrent and scheduled viewing of programs probably to the point that some of the time was spent on doing other activities. These study findings were well supported by ${ }^{15}$ that females who considerably watched TV were more expected to be predisposed to obesity and diabetes mellitus type II. The authors also concluded that the more time spent viewing $\mathrm{TV}$, the greater likelihood of having a higher weight status ${ }^{16}$.

The impact of inheritance cannot be overridden as verified by the greater predisposition for people from an overweight/ obese family member. A study by ${ }^{17}$ also disclosed that individuals are more probable to gain weight (overweight) having at least one family member as overweight, more precisely a parent. In the study, weight gain was also observed in women who were on medications and have systemic diseases such as diabetes mellitus type II, hypertension, heart diseases, cancers (breast cancer or uterine cancer), menopause, polycystic ovarian syndrome i.e. cyst in ovary and musculoskeletal disorders. These findings were well- supported by ${ }^{18-20}$ that weight gain is obvious among individuals taking medicines. Furthermore, study was also well-supported by ${ }^{9}$ as well as ${ }^{10}$ that women who were suffering from systemic diseases are more reliable of having increase of body weight thus accompanying reduced metabolic rate, increase consumption of calories and dwindled physical doings.

\section{Conclusion}

Women life style and systemic factors resulted in increased prevalence of overweight and obesity. The study concluded that overweight and obesity was positively associated with nutritional factors, physical activities and factors such as genetics, use of medications and systemic diseases among women $25-60$ years.

\section{References}

1. Amugsi DA, Dimbuene ZT, Mberu B, Muthuri S, Ezeh AC. Prevalence and time trends in overweight and obesity among urban women: An analysis of demographic and health surveys data from 24 African countries, 1991-2014. BMJ Open. 2017; 7(10):e017344. PMid: 29079606 PMCid: PMC5665233. https:// doi.org/10.1136/bmjopen-2017-017344

2. Doo M, Kim Y. Obesity: Interactions of genome and nutrients intake. Preventive Nutrition and Food Science. 2015; 20(1):1-7. PMid: 25866743 PMCid: PMC4391534. https://doi.org/10.3746/ pnf.2015.20.1.1

3. Singla P. Metabolic effects of obesity: A review. World Journal of Diabetes. 2010; 1(3):76-88. PMid: 21537431 PMCid: PMC3083889. https://doi.org/10.4239/wjd.v1.i3.76

4. Enes CC, Slater B. Variation in dietary intake and physical activity pattern as predictors of change in Body Mass Index (BMI) Z-score among Brazilian adolescents*. Revista Brasileira de Epidemiologia. 2013; 16(2):493-501. PMid: 24142019. https:// doi.org/10.1590/S1415-790X2013000200023

5. Majeed F. Association of BMI with diet and physical activity of female medical students at the University of Dammam, Kingdom of Saudi Arabia. Journal of Taibah University Medical Sciences. 2015; 10(2):188-96. https://doi.org/10.1016/j .jtumed.2014.11.004

6. Tripathy JP, Thakur JS, Jeet G, Chawla S, Jain S, Prasad R. Urban rural differences in diet, physical activity and obesity in India: Are we witnessing the great Indian equalisation? Results from a cross-sectional STEPS survey. BMC Public Health. 2016; 16:816. PMid: 27538686 PMCid: PMC4989330. https://doi .org/10.1186/s12889-016-3489-8

7. Ghadiri-Anari A, Jafarizadah M, Zare A, Mozaffari-Khosravi $\mathrm{H}$, Ardekani AS. Prevalence of obesity and overweight among adults in Iranian population (Yazd Province). Iranian Journal of Diabetes and Obesity. 2014; 5(2):67-70.

8. Correll CU, Detraux J, Lepeleire JD, Hert MD. Effects of antipsychotics, antidepressants and mood stabilizers on risk for physical diseases in people with schizophrenia, depression and bipolar disorder. World Psychiatry. 2015; 14(2):119-36. PMid: 26043321 PMCid: PMC4471960. https://doi.org/10.1002/wps.20204 
9. Kapoor E, Collazo-Clavell ML, Faubion SS. Weight gain in women at midlife: A concise review of the pathophysiology and strategies for management. Mayo Clinic Proceedings. 2017; 92(10):1552-8. PMid: 28982486. https://doi.org/10.1016/j.mayocp.2017.08.004

10. Lumsden MA, Hor K. Impact of obesity on the health of women in midlife. The Obstetrician and Gynaecologist. 2015; 17(3):2018. https://doi.org/10.1111/tog.12199

11. Tariq R, Tariq K. Overweight and obesity; comorbidities among 25-60 years women in Lahore, Pakistan. The Professional Medical Journal. 2017; 24(11):1635-46. https://doi.org/10.17957/ TPMJ/17.3882

12. Buscemi J, Rybak TM, Berlin KS, Murphy JG, Raynor HA. Impact of food craving and calorie intake on Body Mass Index (BMI) changes during an 18-month behavioral weight loss trial. Journal of Behavioral Medicine. 2017; 40(4):565-73. PMid: 28083824 PMCid: PMC5501996. https://doi.org/10.1007/s10865-0179824-4

13. Vogli RD, Kouvonen A, Gimeno D. The influence of market deregulation on fast food consumption and Body Mass Index: A cross-national time series analysis. Bulletin of the World Health Organization. 2014; 92(2): 99-107. PMid: 24623903 PMCid: PMC3949530. https://doi.org/10.2471/BLT.13.120287

14. Strasser B. Physical activity in obesity and metabolic syndrome. Annals of the New York Academy of Sciences. 2013; 1281(1):141-59. PMid: 23167451 PMCid: PMC3715111. https:// doi.org/10.1111/j.1749-6632.2012.06785.x

15. Aryee P, Helegbe G, Baah B, Sarfo-Asante R, Quist-Therson R. Prevalence and risk factors for overweight and obesity among nurses in the Tamale Metropolis of Ghana. Journal of Medical and Biomedical Sciences. 2013; 2(4):13. https://doi.org/10.4314/ jmbs.v2i4.3

16. Rosiek A, Maciejewska N, Leksowski K, Rosiek-Kryszewska A, Leksowski $Ł$. Effect of television on obesity and excess of weight and consequences of health. International Journal of Environmental Research and Public Health. 2015; 12(8):9408-26. PMid: 26274965 PMCid: PMC4555288. https://doi.org/10.3390/ ijerph120809408

17. Phillips EA, Comeau DL, Pisa PT, Stein AD, Norris SA. Perceptions of diet, physical activity and obesity-related health among black daughter-mother pairs in Soweto, South Africa: A qualitative study. BMC Public Health. 2016; 16(1):1-10. PMid: 27506678 PMCid: PMC4977727.https://doi.org/10.1186/s12889016-3436-8

18. Bradshaw T, Mairs H. Obesity and serious mental ill health: A critical review of the literature. Healthcare. 2014; 2(2):166-82. PMid: 27429268 PMCid: PMC4934464. https://doi.org/10.3390/ healthcare2020166

19. Grundy A, Cotterchio M, Kirsh VA, Kreiger N. Associations between anxiety, depression, antidepressant medication, obesity and weight gain among Canadian women. PLoS ONE. 2014; 9(6):e99780. PMid: 24932472 PMCid: PMC4059657. https://doi. org/10.1371/journal.pone.0099780

20. Dayabandara $M$, Hanwella $R$, Ratnatunga S, Seneviratne S, Suraweera C, Silva VD. Antipsychotic-associated weight gain: Management strategies and impact on treatment adherence. Neuropsychiatric Disease and Treatment. 2017; 13:2231-41. PMid: 28883731 PMCid: PMC5574691. https://doi.org/10.2147/ NDT.S113099 